KLEIN, R. (1989) The role of health economics. British Medical Journal, 229, 275-276.

HARRIS, J. (1987) QALYfying the value of life. Journal of Medical Ethics, 13, 117-123.

LOOMES, G. \& McKenZie, L. (1989) The use of gALYs in health care decision making. Social Science \& Medicine, 238, 299-308.

McNeil, B.J., Weichselbaum, R. \& Pauker, S.G. (1981) Speech and survival: tradeoffs between quality and quantity of life in laryngeal cancer. New England Journal of Medictne, 305, 982-987.

MENZEL, P.T. (1992) Oregon's dental: disabilities and quality of life. Hastings Center Report, 22, 21-25.

OYEBODE, F., CUMELIA, S., GARDEN, G. \& NiCHOLLS, J. (1992) Development of outcome measures in acute psychiatry. Psychiatric Bulletin, 16, 618-619.

RAWLS, J. (1971) A Theory of Justice. Oxford: Oxford University Press.
ROSSER, R. \& WATTS, V.C. (1972) The measurement of hospital output. International Journal of Epidemiology, 1 , 361-368.

SPIEGElHAlter, D.J., GoRe, S.M., FITZPATRICK, R., Fletcher, A.E. et al (1992) Quality of life measures in health care. III: resource allocation. British Medical Journal, 308. 1205-1209.

WILKInson, G., Croft-Jeffreys, C., KREKorian, H. et al (1990) GALYs in psychiatric care. Psychiatric Bulletin, 14, 582-585.

WrLiams, A. (1985) The value of GALYs. Health \& Social Services Journal, XCIV, 4957.

Femi Oyebode, Consultant Psychiatrist, Queen Elizabeth Psychiatric Hospital, Mindelsohn Way, Edgbaston, Birmingham B15 2QZ

\title{
The pattern of delays in Mental Health Review Tribunals
}

\author{
Stephen Blumenthal and Simon Wessely
}

\begin{abstract}
Mental Health Review Tribunals (MHRTs) are intended to protect the liberty of the detained patient. In practice, however, they have been said to fall short of providing this safeguard. This is frequently for administrative reasons. We report a systematic examination of the pattern of delays in holding MHRTs. Our main finding is that delay cannot be aftributed to a single factor but rather rellects the inherent complexity of some cases.
\end{abstract}

It is estimated that it takes an average of 24 weeks to arrange Tribunals for applicants who are detained under a restriction order and 15 weeks for non-restricted patients (Department of Health, 1993). For a patient detained on a six month order (section 3 of the Mental Health Act, 1983) Tribunals are often held at the end of their period of detention when the patient may be close to release anyway, the delay therefore negating the purpose of the Tribunal.

\section{The study}

The study was divided into two phases. The first, retrospective study, involved an examination of 150 Tribunal applications selected at random from the four regional Tribunal offices which had taken place over the past five years. The second, prospective stage, was a more detailed examin- ation of factors identified in the first phase. Two hundred Tribunal applications were randomly selected from the four regional Tribunal offices. They were tagged upon receipt and tracked until completion which meant withdrawal of application, discharge prior to the hearing, or the communication of a decision. Section 2 applications were excluded as there are no problems with delay in these cases. In both phases of the study we intentionally oversampled special hospital cases in order that half the sample were taken from the NHS and half from special hospitals.

Social workers and responsible medical officers involved in each of the 200 tagged prospective Tribunals were identified and sent a questionnaire and we examined the effect of responses on the time taken to the submission of reports. Information was also collected from each of the patients' files at the MHRT offices.

We used survival analysis to determine the extent to which various factors contributed to Tribunal delay. The relevant statistic is a hazard ratio, both crude and adjusted. The relative size of the hazard ratio is a measure of the extent to which the particular variable contributes to delay. 
Table 1. Median number of days between application and hearing

\begin{tabular}{lll}
\hline & Restricted & Unrestricted \\
\hline Special hospital & 195 & 132 \\
General & $n=85$ & $n=36$ \\
& 146 & 77 \\
& $n=30$ & $n=70$ \\
\hline
\end{tabular}

\section{Findings}

The key outcome variable for the regression models was the time taken between the patient's application and the Tribunal hearing. We also examined the time taken to the submission of the psychiatric and social circumstances reports. In each case, retrospective and prospective study samples were combined where variables from both phases of the study were avallable.

\section{Time taken to the hearing}

The combined study sample was 350 Tribunal applications. Two hundred and five of these applications resulted in a Tribunal hearing and 16 had not had an outcome by the end of the study period. Therefore 221 cases are included in the following analysis.

Table I indicates the median length of time in days between application and Tribunal hearing for the combined sample.

After appropriate adjustment, restriction orders were associated with a hazard ratio of 2.8 (2.1-3.8), and special hospital status with 3.0 $(2.2-4.0)$.

Eighty-two per cent of patients were represented. In all cases, independent psychiatric reports (IPRs) were requested by a patient representative. IPRs were strongly associated with Tribunal delay. The time to hearing correlated significantly with the time to the IPR $(r=0.72)$. The effect of the IPR on delay persisted even when adjustment was made for special hospital and restriction order (1.5 [1.1-2.1]).

Significantly more patients who were represented were discharged by the Tribunal $\left(\chi^{2}=5.4\right.$; $P=0.02$ ).

Time taken to the psychiatric report

Out of the 200 cases tagged at the start of the prospective study, 154 reports were prepared and sent to the regional Tribunal offices. Replies were received from 79 RMOs who were responsible for 130 of the 154 reports $(84 \%)$.

We found a moderate correlation between the length of time taken to the Tribunal hearing and the time taken to prepare the psychiatric report $(r=0.49)$.
The adjusted hazard ratio for the special hospital group was $1.4(1.0-1.90)$ and for the restricted group 1.5 (1.1-2.0).

We examined whether consultants' attitudes had any effect on the length of time taken by them to prepare psychiatric reports. Neither the priority given to Tribunals, nor views on the role and functioning of the Tribunal, had any bearing on the time to the psychiatric report.

\section{Time taken to the Social Circumstances Report}

Out of the 200 cases tagged at the start of the prospective study, 151 reports were prepared and sent to the regional Tribunal offices. The 93 social workers who replied to the questionnaire covered 101 of the 151 reports $(67 \%)$.

There was a significant correlation between the length of time to the social circumstances report and the time to the Tribunal hearing ( $r=0.51)$. There was also a significant correlation between the length of time taken to the psychiatric and social circumstances reports $(0.66)$ despite the two reports being prepared independently.

The adjusted hazard ratio for the special hospital group was $2.5(1.8-3.4)$ and for the restricted group $1.8(1.3-2.4)$. None of the questions concerning personal views on MHRTs had any effect on the time taken for the submission of reports. However, the number of reports a social worker was expected to produce in an average month did influence the time to preparation $(P<0.05)$ - the more reports, the greater the delay.

\section{Comment}

We conclude that MHRT delay cannot be attributed to a single factor in isolation. Some Tribunals are inherently more complex than others, resulting in reports from the various individuals and agencies involved in the particular patient's care all being delayed. A number of factors contribute.

First, examination of these variables reveals that patients detained under a restriction order and in a special hospital took about two and a half times longer to have their Tribunal hearing than those who were unrestricted and in the NHS. This difference is substantially more than that set by the Pudlo targets (Pudlo, 1987) - the 12 and eight week norms allow only a one and a half times difference between restricted and unrestricted cases. In particular, these targets do not take account of the volume of Mental Health Act work for special hospital consultants and social workers.

Second, Tribunals have become increasingly legalistic and consequently take longer. In 1989 
$65 \%$ of patients appeared with representation (Genn \& Genn, 1989). Four years later this has risen to $82 \%$ in this study.

There was also a strong association between representation and requesting an independent psychiatric report. Adjournments also resulted from requests for IPRs and are inevitably caused by solicitors. However, patients who were represented have a better prospect of discharge at the Tribunal.

Third, a frequent complaint from clerks in the regional Tribunal offices is the lack of judge time. Provisional data collected by the Department of Health suggest that the lack of judge time is a further contributor to delay. However, the effect of the availability of judges on delay could not be examined systematically, since judges sit on all restricted cases. Instead, we are only able to report anecdotal opinion.

Fourth, there has been a dramatic increase in the number of applications for section 2 Tribunal hearings, the annual figure now approaching 3,000 (Council on Tribunals, 1992). Section 2 hearings put considerable pressure on the Tribunal system since they must be convened rapidly and yet are often cancelled at the last minute because the patient has been discharged. There are no delays in these cases, but perhaps this has only been achieved at the cost of adding delays in other cases.

Finally, despite claims to the contrary, Home Office delay did not appear to make a substantia contribution to the time taken for hearing restricted cases.
We found no firm evidence that delay resulted in a better outcome from the patients' point of view. Although there were links between legal representation, independent psychiatric reports and discharge, there was no overall association between delay and discharge.

\section{Acknowledgements}

We are grateful to the all professionals - Tribunal members, Mental Health Act administrators, social workers, psychiatrists and legal representatives - and patients who participated in the survey. The study was funded by the Department of Health. The views expressed are entirely our own.

\section{References}

COUNCR ON Tribunals (1992) Annual Report. London: HMSO.

DEPARTMENT OF HEALTH (1993) Unpublished statistics.

GENN, H. \& GENN, Y. (1989) The Effectiveness of Representation at Tribunals. Unpublished report to the Lord Chancellor's Department.

PudLo, P. (1987) Mental Health Review Tribunal Delays. Unpublished Department of Health Report.

Stephen Blumenthal, Researcher; and Simon Wessely, Sentor Lecturer in Psychological Medicine, Department of Psychological Medictne, King's College Hospital, Denmark Hul, London SE5 9RS 